\title{
1500076: Re-thinking UK transport emissions - getting to the 2050 targets
}

By Heleni Pantelidou, Gerard Casey, Tim Chapman, Peter Guthrie and Kenichi Soga (November 2016)

\section{Contribution by Lloyd Roberts}

I would like to thank the authors

for a very useful and instructive paper.

The difficulty with reducing reliance on roads for much of Britain's freight transport is that most freight is in relatively small units and there is a lack of private rail sidings. Containerisation has achieved some success, but the convenience of smaller loads conveyed door-to-door by road ensures that transfer to rail is not looked on favourably.

One solution not referred to in the paper is the adoption of Eurotunnel Shuttle-style roll-on-roll-off facilities for trunk hauls within the UK. Normal lorries could simply drive on to frequent and attractively priced train ferries for the trunk haul of their journeys and complete the short legs to and from railheads by road. This would combine the convenience of door-to-door delivery with the reduction in emissions for the bulk of the journey achieved through convenient and fast loading of the lorries (and cars for that matter) onto rail wagons.

With the high speeds possible by rail and the savings in fuel and possibly drivers' hours, it could be attractive in terms of cost and time. The reduction in freight traffic on motorways would also delay the need for further road widening or other capacity improvement schemes. Furthermore, if a substantial proportion of the heavy goods vehicle traffic was taken off the motorways, maintenance would be much reduced given that a typical lorry damages the road surface about 1000 times more than a typical car. Safety and reliability would also be increased.

Looking to the future, perhaps all new rail lines and improvements to existing lines should require an adequate loading gauge to allow for roll-on-roll-off wagons. Can the authors indicate if they have done any research into the feasibility of this option?

\section{Authors' reply}

The authors understand that new railway lines such as High Speed 1 and 2 are designed to a larger gauge to enable larger trains to run, although the high line speeds are incompatible with efficient use by freight trains

It is a sad fact that rail freight in the UK is currently in decline, although this is mainly driven by a reduction in bulk coal loads to power stations - consistent with a 'decarbonisation' of the UK's electricity mix.

The paper already laments that rail is not used enough for freight and so mode shift would be very beneficial for the UK for the reasons cited, both in the paper and by the contributor. The UK rail freight industry would benefit by some high-level policy support to make it more attractive and thereby enable such a mode shift to take place.

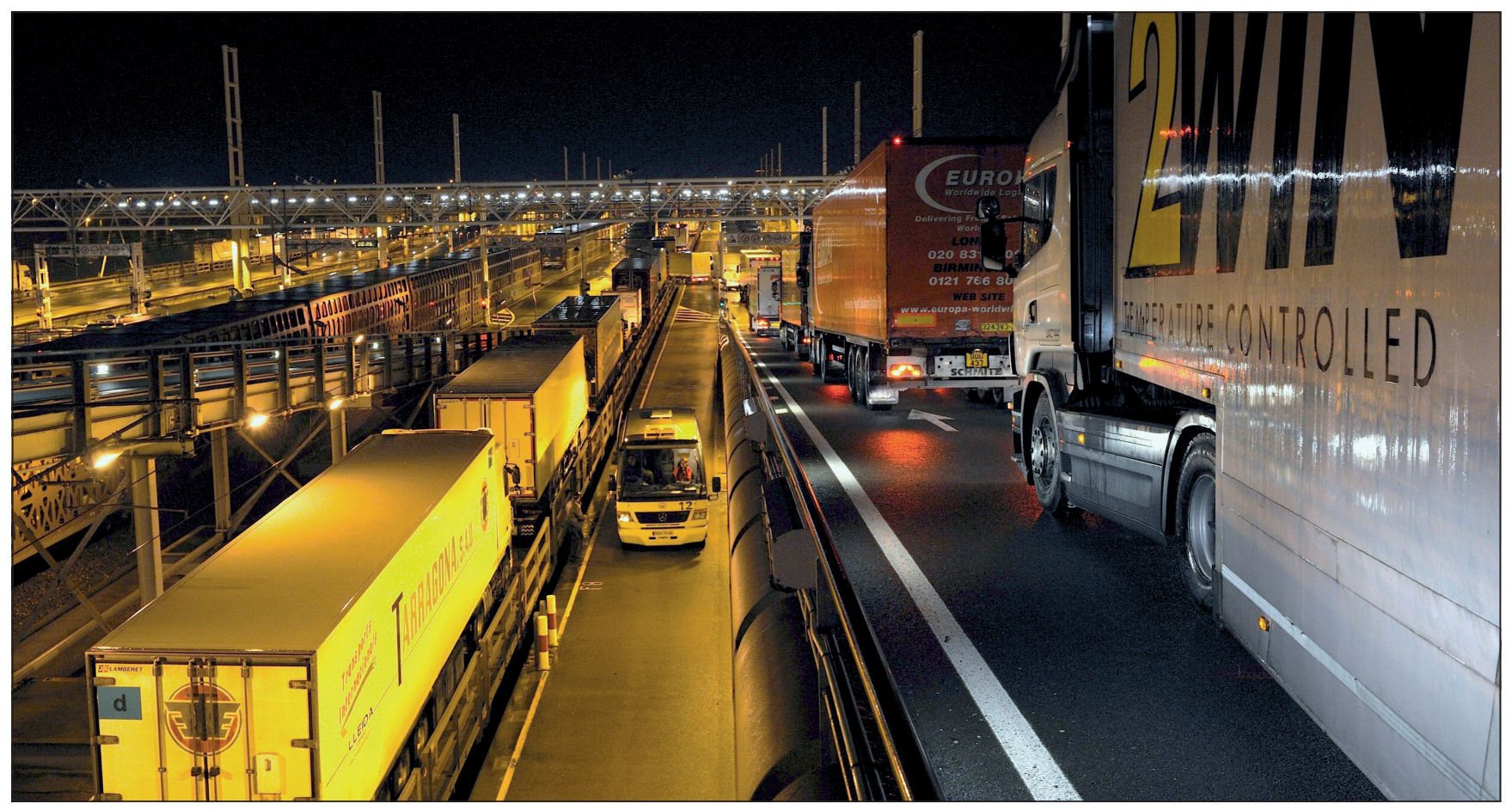

Why not build Eurotunnel Shuttle-style roll-on-roll-off facilities on major haul routes in the UK? (copyright Eurotunnel) 